\title{
El concepto de seguridad social
}

\author{
Francisco Henao Machado \\ Coordinador General del Seminario
}

Comencemos por circunscribir un marco de referencia para el Seminario y ponernos de acuerdo sobre que es la seguridad social; cuáles sus propósitos, sus quehaceres habituales; los diversos enfoques posibles y sus respectivas connotaciones.

\section{Actualidad del tema}

Tres hechos de actualidad relievan la importancia que tradicionalmente le hemos reconocido al tema:

1.1. La Conferencia Mundial de Rio de Janeiro, que se reúne para discutir sobre la ecología, la protección de la tierra y el uso racional de los recursos, constituye una manera de proteger al hombre mismo. Esto, en alguna medida, es también seguridad social, porque despeja el panorama futuro de las comunidades humanas.

1.2. Otro acontecimiento de singular trascendencia es la Constitución colombiana de 1991 , que introdujo una orientación bastante avanzada de la seguridad social.

1.3. El tercer hecho es el consenso que hoy existe para realizar un cambio urgente y trascendental en la protección de la gente, es decir, en materia de seguridad social.

\section{Bienestar de las personas}

Vamos a plantear unos hitos, unos puntos estructurales, para el desarrollo posterior del Seminario: 
2.1. Toda persona tiene un nivel de bienestar y aspira a un nivel de bienestar esencialmente variable, que está determinado por la edad de la persona, sus condicionantes familiares, de trabajo, de grupo, de comunidad. De tal manera que el bienestar no es igual para todo el mundo porque tiene características subjetivas muy cambiantes.

2.2. El grado de bienestar dado por la manera como se logren llenar las necesidades y aspiraciones de cada persona.

2.3. Entendemos por necesidades, aquellas que deba obtener la persona para subsistir en forma adecuada a su grado de desarrollo y que le permitan desenvolverse fisica y psicológicamente.

Pueden identificarse como necesidades más elementales las de alimentación, vestido, vivienda. A este nivel de necesidades básicas deben llegar todas las personas sin distingos de ninguna naturaleza.

2.4. Las aspiraciones son aquellas cosas o metas a las cuales la persona quisiera llegar en alguna etapa de su vida.

\section{Bienes y servicios}

3.1. Desde el punto de vista económico y de organización social, tenemos una serie de bienes y servicios para atender las necesidades y aspiraciones de la persona.

3.2. Bienes son las cosas más perdurables, que aguantan múltiples usos, como por ejemplo, la vivienda.

3.3. Servicios son aquellas cosas que se desgastan en la utilización, que se consumen, vgr. la salud.

3.4. Para medir el bienestar de la gente (las necesidades y aspiraciones; los bienes y servicios) se han inventado diversas metodologías. Por ejemplo, los denominados niveles de vida, de la Organización de las Naciones Unidas, que incluyen el empleo, la vivienda, la educación, la alimentación, el vestido, la salud.

\section{Costos del bienestar}

4.1. Los bienes y servicios tienen unos costos. Esto significa que el individuo debe tener un poder de consumo o de adquisición.

4.2. Lo más común es que esa capacidad de adquisición de bienes y de servicios provenga de tres fuentes:

$$
\text { - del empleo }
$$

reditúa, y

- de un capital que

- de las relaciones de dependencia. Vgr. con los padres o con el Estado.

4.3. La seguridad social ha sido la universal preocupación 
para dar protección a la gente de una comunidad para que pueda vivir adecuadamente. Esto es, que llene sus necesidades y aspiraciones en la medida del grado de desarrollo de su comunidad.

\section{Riesgos}

5.1. Los riesgos se definen como las probabilidades de interrupción en los ingresos (vgr. por muerte o incapacidad de la persona) o de cambios en la situación familiar (vgr. el número de sus miembros).

5.2.Los riesgos pueden clasificarse en:

- Riesgos biológicos, que menoscaban la condición de la persona en cuanto ser vivo, como el envejecimiento, la enfermedad y la muerte.

- Riesgos sociales, que derivan de la condición de pertenecer a un grupo (como la educación, el trabajo, una huelga, la inmigración, entre otros) para lo cual se han elaborado dos tipos de bienes y servicios: los culturales y los sociales.

\section{Surgimiento}

\section{de la seguridad social}

6.1. La moderna seguridad social halla sus precedentes en las asociaciones que la iglesia promovía alrededor de las parro- quias para proteger a sus feligreses: cada quien ponía una cuota y formaban un fondo muy simple.

6.2. En Alemania el gobierno tuvo la iniciativa de brindar protección a los trabajadores de las ciudades y a sus familias de acuerdo con un modelo de seguros sociales.

6.3. Sobre este esquema de relaciones industria-trabajador, la seguridad Social tradicionalmente ha excluido al resto de la comunidad.

\section{Panorama de la seguridad social}

7.1. Es muy heterogéneo y multi-institucional el panorama de la seguridad social en Latinoamérica, que da lugar a duplicidades, ineficiencias y falta de cobertura.

7.2. Para resumir, podemos decir que la moderna seguridad social es aquella política del Estado, que permite a todos los individuos, estar protegidos contra todos los riesgos, durante toda su existencia.

7.3. Las mínimas condiciones de una adecuada subsistencia para todos, sería el límite inferior de la seguridad social. Hasta un límite superior que sería el máximo que se pueda garantizar a todo el mundo.

7.4. La financiación de los bienes y servicios de la seguridad social puede provenir de un 
mecanismo tripartito de cotizaciones: de las empresas, los trabajadores y el Estado.

7.5. Pero dentro de la seguridad social, como la estamos entendiendo, el mecanismo de financiación es del Estado, con todo lo que esto significa.

\section{Contenido de la seguridad social}

8.1. El contenido de la seguridad social ha sido, por importancia y por razones históricas, la salud y las prestaciones económicas. Sin embargo, al pretender manejarlas en forma conjunta, resulta que ambas se hacen daño mutuamente.

8.2. La atención de la salud en forma integral, desde las actividades de fomento hasta la rehabilitación, es costosa y de un gasto inmediato, que conduce fre- cuentemente a echar mano de las reservas económicas provistas para las pensiones.

8.3. Por fortuna, ahora en Colombia se abre paso la idea de separar estos grandes rubros. Los riesgos, como los de salud, son los que primero hacen crisis en todos los países.

8.4. De otro lado, las obligaciones pensionales con el tiempo también hacen crisis, de una manera más alarmante.

\section{Conclusión}

Se requiere con urgencia un profundo cambio en materia de seguridad social para mejorar el nivel de vida de las gentes más pobres; procurándoles una igualdad de oportunidades y, sobre todo, un mínimo de bienestar. 